\title{
Intervenção comportamental em políticas públicas brasileiras: o caso da lei 12.618/2012
}

\author{
Behavioral intervention in brazilian public policies: the case of law 12.618/2012
}

Intervención conductual en políticas públicas brasileñas: el caso de ley 12.618 / 2012

Igor Feitosa Lacorte Ayroza

ORCID: https://orcid.org/0000-0001-6441-8199

Universidade Federal do Tocantins, Brasil

E-mail: Igor.Ayroza@uft.edu.br

Waldecy Rodrigues

ORCID: https://orcid.org/0000-0002-5584-6586

Universidade Federal do Tocantins, Brasil

E-mail: waldecy@terra.com.br

Manoel Xavier Pedroza Filho

ORCID: https://orcid.org/0000-0003-4144-0654 Universidade Federal do Tocantins, Brasil

E-mail: manuel.pedroza@embrapa.br

Leonardo de Andrade Carneiro

ORCID: https://orcid.org/0000-0003-2388-7516

Universidade Federal do Tocantins, Brasil

E-mail: leodpalmas@hotmail.com

\begin{abstract}
Resumo
Contexto: no Brasil, o uso de intervenções comportamentais (IC) em políticas públicas (PP) ainda é incipiente. Objetivo: o presente trabalho tem como objetivo analisar a IC, em uma experiência pioneira na utilização da Economia Comportamental (EC) no design de PP no Brasil, criada para instituir o regime de previdência complementar dos servidores públicos federais. Métodos: o estudo de caso foi realizado utilizando dados dos portais da FUNPRESP, Transparência e Painel PEP e análise documental. Na abordagem qualitativa, foi utilizada a hermenêutica jurídica para interpretar o sentido e aplicação das normas envolvidas no estudo buscando a ampliação das possibilidades de sua compreensão. Resultados: indicam que a IC contribuiu para o aumento significativo do número de participantes no plano de previdência complementar e o aumento de adesões voluntárias por meio de campanhas que mitigaram os efeitos das heurísticas e vises cognitivos predominantes no processo de decisão relacionado à adesão de planos de previdência. Conclusões: fica evidenciada que a utilização dos conhecimentos da EC na previdenciária potencializa os resultados da política. Porém, por se tratar da análise de um caso específico, não se tem indícios suficientes para se generalizar a eficácia das intervenções comportamentais em políticas públicas.
\end{abstract}

Palavras-chave: Economia comportamental; Políticas públicas; FUNPRESP; Heurísticas e vieses comportamentais; Previdência complementar.

\begin{abstract}
Context: in Brazil, the use of behavioral interventions (BI) in public policies (PP) is still incipient. Objective: the present work aims to analyze BI, in a pioneering experience in the use of Behavioral Economics (BE) in the design of PP in Brazil, created to institute the supplementary pension scheme of federal public servants. Methods: the case study was carried out using data from FUNPRESP portals, Transparency and PEP Panel and document analysis. In the qualitative approach, legal hermeneutics was used to interpret the meaning and application of the norms involved in the study, seeking to expand the possibilities of their understanding. Results: indicate that BI contributed to the significant increase in the number of participants in the supplementary pension plan and the increase in voluntary participation through campaigns that mitigated the effects of heuristics and cognitive biases predominant in the decision-making process related to the adoption of pension plans. Conclusions: thus, it is evidenced that the use of BE knowledge in social security enhances the results of the policy. However, because it is the analysis of a specific case, there is insufficient evidence to generalize the effectiveness of behavioral interventions in public policies.
\end{abstract}

Keywords: Behavioral economics; Public policy; FUNPRESP; Heuristics and behavioral vieses; Supplementary pension.

\section{Resumen}

Contexto: en Brasil, el uso de intervenciones conductuales (IC) en políticas públicas (PP) es aún incipiente. Objetivo: el presente trabajo tiene como objetivo analizar la IC, en una experiencia pionera en el uso de la Economía Conductual 
(EC) en el diseño de PP en Brasil, creada para instituir el esquema de pensión complementaria para los servidores públicos federales. Métodos: el estudio de caso se realizó utilizando datos de los portales FUNPRESP, Panel Transparencia y PEP y análisis documental. En el abordaje cualitativo se utilizó la hermenéutica jurídica para interpretar el significado y aplicación de las reglas involucradas en el estudio, buscando ampliar las posibilidades de su comprensión. Resultados: indican que el IC contribuyó al aumento significativo del número de participantes en el plan de pensión complementaria y al aumento de las adhesiones voluntarias a través de campañas que mitigaron los efectos de las visiones heurísticas y cognitivas prevalentes en el proceso de decisión relacionado con la adhesión de planes de seguro. seguridad Social. Conclusiones: es evidente que el uso del conocimiento de la EC en el sistema de seguridad social mejora los resultados de la política. Sin embargo, al tratarse de un análisis de un caso específico, no existe evidencia suficiente para generalizar la efectividad de las intervenciones conductuales en las políticas públicas.

Palabras clave: Economía conductual; Políticas públicas; FUNPRESP; Sesgos heurísticos y conductuales; Pensión complementaria.

\section{Introdução}

A Economia Comportamental (EC) é orientada para práticas e direções econômicas, podendo deste modo, contribuir na orientação de políticas públicas. É uma abordagem das ciências econômicas criada no início dos anos 50 a partir da contestação dos modelos teóricos propostos pela abordagem neoclássica da economia (Simon, 1955). Este novo campo das ciências econômicas se utilizou de conhecimentos das áreas da psicologia e outras ciências sociais para construir sua base teórica e experimental como alternativa às teorias econômicas tradicionais baseadas na otimização dos resultados (Camerer, 2014).

Embora via de regra formuladores de políticas sejam influenciados pelas proposições oriundas da economia neoclássica, recentemente, suscitou-se a utilização da economia comportamental no desenho e formulação de políticas públicas (Bhargava \& Loewenstein, 2015). (Estudiosos da área Thaler \& Sunstein, 2009; Low, 2012; Soman, 2015) perceberam que políticas públicas (PP) baseadas no modelo econômico tradicional não estavam produzindo os resultados esperados e buscaram soluções alternativas para fundamentar tais políticas. Desta forma, políticas públicas influenciadas pela economia comportamental passaram a ser desenhadas e formuladas nas mais diversas áreas, a saber: saúde, finanças, direito, previdência e educação (Soman, 2014).

Estados Unidos e Reino Unido são exemplos de países que utilizam intervenções comportamentais em políticas públicas. Nestes países foram criados órgãos vinculados ao governo, responsáveis por estudar e propor leis e políticas que utilizam intervenções comportamentais para alcançar seus objetivos. Nos Estados Unidos foi criado o Social and Behavioral Sciences Team (SBST) e no Reino Unido foi criado o Behavioral Insights Team (BIT) (Team, 2014).

A equipe de economia comportamental do Banco Mundial (eMBeD) divulgou um estudo em que teve como objetivo verificar como os formuladores de políticas públicas de alguns países aplicam os insights comportamentais na solução de problemas. Tal estudo destacou a importância da criação do BIT no Reino Unido no ano de 2010 para o desenvolvimento, expansão e estruturação de equipes especializadas no planejamento, formulação, execução e avaliação de políticas públicas de cunho de comportamental ao redor do mundo (World, 2019).

Outro ponto abordado foi o amadurecimento dos pesquisadores da área, o que possibilitou a padronização de "suas ferramentas, abordagens e incorporação da ciência comportamental em procedimentos padronizados de design e implementação de políticas públicas, como visto em algumas das unidades na Holanda e no Reino Unido (World, 2019)”. Após um início onde os estudos eram realizados de forma independente, buscou-se uniformizar as metodologias utilizadas nas pesquisas a fim de conferir maior credibilidade ao campo.

De acordo com dados da Organização para a Cooperação e Desenvolvimento Econômico (OCDE, 2018) até o final do ano de 2018 existiam 202 entidades públicas especializadas na aplicação de insights comportamentais na formulação de políticas públicas. Entretanto, mesmo com a expansão vertiginosa das unidades de estudos comportamentais, a OECD destacou a limitação do uso dos conhecimentos das ciências comportamentais na formulação de políticas públicas. 
A maioria das experiências no campo encontra-se em fase de testes e não fornece dados mais aprofundados a respeito da eficácia da utilização dos insights comportamentais na implementação de políticas. Mesmo em países onde os departamentos de economia comportamental estão bem estabelecidos ainda não se sabe ao certo se serão definitivamente integrados ao processo de planejamento, desenvolvimento e implementação de políticas ou, se terão apenas função auxiliar, dispondo de seu extenso arcabouço teórico-metodológico para os formuladores de políticas, mas sem, no entanto, ter garantias de que os conhecimentos produzidos serão efetivamente testados e aplicados ao caso concreto (World, 2019).

Em contrapartida, pesquisadores do Banco Mundial destacaram a utilização dos insights comportamentais associados a outros tipos de inovações, ou seja, utilização dos princípios da EC no desenvolvimento de tecnologias como o Big Data, inteligência artificial, aprendizado de máquina e realidade virtual. Eles entendem que através destas experiências será possível utilizar os conhecimentos acumulados na elaboração de políticas públicas voltadas a regulamentação destes temas: aprendizado de maquinas (machine learning), inteligência artificial e analise comportamental preditiva (World, 2019).

Campos Filho e Paiva (2018) fizeram uma relevante síntese de ações da economia comportamental aplicadas às políticas públicas por parte de alguns organismos internacionais. A começar pelo ano de 2015, os autores destacam a atenção dada ao assunto pelo Banco Mundial, que destinou sua principal publicação (World Development Report) para discutir os principais avanços da área em âmbito mundial.

No ano de 2016 foi destacado estudo realizado pela União Europeia onde foram identificadas mais de 200 iniciativas em 32 países de intervenções comportamentais realizadas em políticas públicas. Por fim, os autores enfatizaram o relatório Behavioural Insights na Public Policy: Lessons from Around the World publicado pela Organização para a Cooperação e Desenvolvimento Econômico (OCDE, 2017). Neste relatório identificou-se 159 estudos de caso aplicando insights comportamentais em 23 países.

Percebe-se que internacionalmente, importantes instituições têm se dedicado a estudar e compreender os efeitos das intervenções comportamentais nas políticas públicas. Neste sentido alguns países têm dispendido um esforço hercúleo para demonstrar a seus governos o valor dos conhecimentos oriundos da Economia Comportamental.

É o caso da Austrália, Canadá, Dinamarca, França, Alemanha, Holanda, Áustria, Reino Unido, Singapura e Estados Unidos. Nos países mencionados, os estudos no campo da Economia Comportamental aplicados às políticas públicas já estão bem difundidos e estruturados possuindo diversas pesquisas e trabalhos científicos. Entretanto, no Brasil os estudos na área ainda carecem da substancialidade das ações vistas em outros países.

Os estudos realizados ocorrem de maneira esparsa e descoordenadamente em âmbito nacional. Como exemplo, não existe nenhum órgão brasileiro em âmbito federal que seja responsável pela coordenação de ações e intervenções de cunho comportamental, tais como o SBST (Estados Unidos) e o BIT (Reino Unido) citados anteriormente.

Mesmo com a ausência de uma instituição fomentadora de políticas públicas de cunho comportamental no país, algumas políticas utilizaram intervenções comportamentais para alcançar seus objetivos. É o caso da portaria $\mathrm{n}^{\circ}$ 540/2004 (atualmente Portaria Interministerial $\mathrm{n}^{\circ}$ 4, de 11 de maio de 2016) do antigo Ministério do Trabalho e Emprego (MTE), atual Secretária Especial de Previdência e Trabalho vinculada ao Ministério da Economia, que instituiu o Cadastro de Empregadores, e da lei $n^{\circ}$ 12.618/2012 que instituiu o regime de previdência complementar para os servidores públicos federais titulares de cargo efetivo.

A portaria trata da criação de uma "lista suja" onde são adicionadas as empresas que se utilizam de pessoas para trabalharem em condições análogas à de escravo a fim de inibir a prática por meio da publicidade dos atos considerados contrários aos valores sociais vigentes. No entanto, a lei previdenciária $n^{\circ} 12.618 / 2012$ por ser uma norma jurídica hierarquicamente superior a portaria em questão, exemplifica com maior amplitude a utilização dos conhecimentos da economia comportamental em políticas públicas no árido cenário nacional. 
A experiência nacional com a aplicação da ciência comportamental aplicada a política não começou da forma planejada. Inicialmente a lei no 12.618/2012 não produziu os resultados esperados com sua criação. Desta forma, a fim de evitar que a lei se constituísse em mais uma lei inefetiva, os formuladores da política alteraram parte de sua redação. Alteraram o padrão de adesão facultativa ao plano para adesão automática. Esta simples alteração de padrão de inscrição se consistiu em uma intervenção comportamental bastante eficaz e foi responsável por converter o "fracasso" inicial da lei em uma experiência exitosa.

Ante o exposto, o presente trabalho tem como objetivo analisar a intervenção comportamental feita na lei previdenciária nº 12.618/2012, iniciativa pioneira na utilização da Economia Comportamental no design de políticas públicas no Brasil, visando identificar as heurísticas e vieses cognitivos que influenciaram sua alteração. Trata-se de uma análise que pretende ilustrar como as intervenções comportamentais podem potencializar os efeitos e auxiliar na consecução dos objetivos das políticas públicas no caso do Brasil, que é incipiente no uso destes instrumentos.

\section{Material e Métodos}

Demonstrar a efetividade da utilização dos conhecimentos e técnicas da Economia Comportamental em políticas públicas é importante pois permite evidenciar como pequenas intervenções, com baixo custo, podem auxiliar os gestores a alcançar os resultados esperados de uma política. E considerando que no Brasil este tipo de intervenção ainda carece de incentivos, estruturação e padronização, analisar as intervenções realizadas, sejam elas exitosas ou não, permite peneirar os conhecimentos e técnicas que podem ser reaproveitados e rearranjados em experiências futuras.

No que tange a metodologia, realizou-se pesquisa qualitativa por se entender que a política analisada pode ser compreendida no contexto em que está inserida, possibilitando sua análise de forma integrada (Godoy, 1995). Optou-se desta forma pela adoção da modalidade estudo de caso para viabilizar o entendimento da política pública de forma mais aprofundada e detalhada (OCDE, 2018; Creswell, 2010). Utilizou-se também a hermenêutica jurídica para interpretar o sentido e aplicação das normas jurídicas envolvidas no estudo buscando a ampliação das possibilidades de sua compreensão e a análise documental para buscar dados e informações contidos nos documentos pesquisados a fim de evidenciar elementos inerentes ao objeto pesquisado (Lüdke \& André, 1986) .

Para realizar a análise dos efeitos da intervenção comportamental em uma política pública brasileira, optou-se pelos seguintes passos metodológicos: 1) sintetização das experiências internacionais a fim verificar como os formuladores de políticas públicas aplicam os insights comportamentais na solução de problemas, com publicações de renomados organismos internacionais como: Banco Mundial, OCDE e União Europeia.; 2) Levantamento e análise de dados e informações referentes aos resultados alcançados pela política pública após a incorporação dos conhecimentos e técnicas da Economia Comportamental

A pesquisa foi realizada utilizando dados secundários dos portais da FUNPRESP, Transparência e Painel PEP (Painel Estatístico de Pessoal ligado ao Ministério do Planejamento) vinculados ao Governos Federal. No primeiro portal foi realizada pesquisa de informações relacionadas ao desenvolvimento e expansão do plano de previdência complementar dos servidores federais. O Portal da Transparência (CGU, 2020) é mantido pela Controladoria Geral da União (CGU) e tem como objetivo garantir a transparência da Gestão pública possibilitando a participação social na fiscalização das despesas públicas do Poder Executivo Federal.

Foi utilizado para a pesquisa do número de servidores ativos no período delimitado para o estudo. Já o Painel PEP (Ministério da economia, 2020) tem o objetivo de simplificar o acesso às informações estatísticas da área de Gestão de Pessoas do governo federal e atualmente é mantido pelo Ministério da Economia. Também foi utilizado para pesquisar a situação dos servidores. O recorte temporal feito para o estudo situa-se entre os anos de 2016 a 2020. 


\section{Resultados e Discussões}

\subsection{Experiências internacionais do uso da economia comportamental em políticas públicas: casos dos Estados Unidos,} Reino Unido e Áustria

Nos Estados Unidos, Thaler e Benartzi (2009) criaram um programa chamado Save More Tomorrow aplicando as ideias da Economia Comportamental em políticas públicas. Através dele, os autores buscaram aumentar a quantidade de adesões aos planos de previdência privados estadunidenses com o intuito de assegurar aos beneficiários qualidade de vida na velhice. Na prática, para aderirem aos diferentes planos disponíveis, os trabalhadores tinham que manifestar seu interesse sobre qual deles iriam escolher, ou seja, o padrão de escolha era “optar pela adesão" (opt out) ao plano.

$\mathrm{Na}$ maioria dos casos, principalmente por falta de informação, os trabalhadores não realizavam a adesão aos planos, o que contribuía para que grande parte deles não poupasse recursos suficientes para gozar de uma aposentadoria tranquila. A intervenção comportamental feita neste caso consistiu em mudar o padrão de escolha para "optar por desvincular" (opt in) do plano. Desta forma, os trabalhadores eram inscritos automaticamente nos planos de previdência e caso não estivessem satisfeitos ou quisessem optar por outros planos mais interessantes, eram livres para agir como quisessem. Em pouco tempo, o programa atingiu altas taxas de participação conquistando resultados significativos.

$\mathrm{Na}$ Áustria, Nudges foram utilizadas com sucesso em políticas de doação de órgãos. O governo austríaco optou por adotar como opção padrão para seus cidadãos a doação de órgãos. Em regra, os austríacos são considerados doadores de órgãos, a menos que optem por não doar, por meio do preenchimento de um formulário, em vida, ou também pela recusa oral de parentes do finado, pós-morte (Sousa Lourenco, Ciriolo, Rafael Almeida, Dessart, 2016). Segundo o Behavioral Insights Applied to Policy, órgão vinculado a União Europeia responsável por elaborar e aplicar políticas públicas embasadas na EC, no ano de 2013 a Áustria ocupou a oitava posição mundial em relação ao número de doadores (falecidos) de órgãos, o que contribuiu para o salvamento de muitas vidas em solo austríaco.

Já no Reino Unido, pode-se citar uma interessante intervenção realizada pelo Behavioral Insights Team (BIT) na área tributária. Em geral, as multas de trânsito eram pagas através do acionamento de oficiais de justiça para a realização da cobrança gerando gastos extras para o governo. Para alterar este quadro, reduzindo gastos desnecessários, o BIT encaminhou mensagens de texto randomicamente para um grupo de devedores, deixando de encaminhar as mensagens para os demais devedores (Team, 2014).

O conteúdo das mensagens alertava sobre a falta do pagamento da multa e que caso não fosse quitada a dívida seria enviado um oficial de justiça para cobrá-lo. Como resultado, houve aumento no número de pagamentos das multas sem a necessidade de acionamento dos oficiais de justiça. No grupo dos devedores que receberam as mensagens de texto, a proporção do número de pagamentos foi de 1 (um) pagante a cada 3 (três) devedores. Já no grupo de devedores que não receberam as mensagens de texto, a proporção do número de pagamentos foi de 1 (um) pagante a cada 20 (vinte) devedores. Através de uma intervenção simples e praticamente sem custos houve economia de gastos por parte do governo vez que foram evitadas idas às ruas de oficiais de justiça para realizarem as cobranças, além de, claro, aumentar a arrecadação com pagamento das multas atrasadas(Team, 2014).

\subsection{O uso de intervenções comportamentais em uma política pública brasileira: o caso da FUNPRESP-EXE}

De acordo com Ávila e Bianchi (2015) a Economia Comportamental (EC) ainda é incipiente no cenário brasileiro. Mesmo carente de coordenação e incentivos, existem experiências pontuais de políticas públicas no Brasil que utilizaram intervenções comportamentais para atingir seus objetivos. Um caso interessante é o da lei no 12.618/2012, responsável pela criação do regime de previdência complementar dos servidores públicos federais, conforme poderá ser visto a seguir. 
No ano de 2012, foi promulgada a lei $\mathrm{n}^{\circ} 12.618$ instituindo o regime de previdência complementar para os servidores públicos federais titulares de cargo efetivo, criando a Fundação de Previdência Complementar do Servidor Público Federal (FUNPRESP) abrangendo cada um dos três poderes: executivo (FUNPREP-EXE), legislativo (FUNPRESP-LEG) e judiciário (FUNPRESP-JUD). Após a lei foi publicado o decreto n ${ }^{\circ}$ 7.808/2012 regulamentando a FUNPRESP-EXE.

Com a finalidade de administrar e executar planos de benefícios de caráter previdenciário complementar para os servidores públicos titulares de cargo efetivo da União, suas autarquias e fundações. A Funpresp é uma fundação sem fins lucrativos, de direito privado, com natureza pública e autonomia administrativa, financeira e gerencial (Brasil, 2012).

Embora a lei tenha criado a FUNPRESP para todos os poderes, cada um deles ficou responsável pela regulamentação das regras de funcionamento da previdência complementar para seus servidores. Identificou-se, porém, que após a vigência da lei houve um baixo índice de adesão aos planos de previdência recém-criados pelo governo (Tabak \& Amaral, 2018). O padrão adotado até então era a livre adesão (opt in) e não vinculação a nenhum dos planos disponíveis, conforme pode ser visto na redação do parágrafo $1^{\circ}$, do artigo $1^{\circ}$, da lei $12.618 / 2012$ :

Art. $1^{\circ}(\ldots)$

Parágrafo único. Os servidores e os membros referidos no caput deste artigo que tenham ingressado no serviço público até a data anterior ao início da vigência do regime de previdência complementar poderão, mediante prévia e expressa opção, aderir ao regime de que trata este artigo, observado o disposto no art. $3^{\circ}$ desta Lei (Brasil, 2012).

Ou seja, após o ingresso no serviço público o servidor deveria escolher entre a adesão ou não aos planos de previdência disponíveis pela Fundação. Com a arquitetura de escolhas da lei configurada desta forma, o número de adesões aos planos foi aquém do esperado.

Após identificação do problema, alguns anos depois, no ano de 2015, foi publicada a lei nº13.183/2015 que alterou o artigo $1^{\circ}$ da lei $12.618 / 2012$ :

Art. $1^{\circ}(\ldots)$

$\S 2^{\circ}$ Os servidores e os membros referidos no caput deste artigo com remuneração superior ao limite máximo estabelecido para os benefícios do Regime Geral de Previdência Social, que venham a ingressar no serviço público a partir do início da vigência do regime de previdência complementar de que trata esta Lei, serão automaticamente inscritos no respectivo plano de previdência complementar desde a data de entrada em exercício.

$\S 3^{\circ}$ Fica assegurado ao participante o direito de requerer, a qualquer tempo, o cancelamento de sua inscrição, nos termos do regulamento do plano de benefícios.

$\S 4^{\circ} \mathrm{Na}$ hipótese do cancelamento ser requerido no prazo de até noventa dias da data da inscrição, fica assegurado o direito à restituição integral das contribuições vertidas, a ser paga em até sessenta dias do pedido de cancelamento, corrigidas monetariamente (Brasil, 2012).

Neste sentido, a partir da utilização da hermenêutica jurídica, verificou-se que a nova redação do artigo mudou o padrão opt in, para o padrão opt out, ou seja, a inscrição nos planos disponíveis na FUNPRESP passou a ser automática, imediata ao ingresso do indivíduo no serviço público federal, de forma que a opção alternativa passou a ser a desvinculação aos planos de previdência (Tabak \& Amaral, 2018) 22 . Caso o servidor não se interessasse em permanecer nos planos oferecidos pela Fundação, a lei possibilitou o cancelamento de sua vinculação a qualquer tempo. Esta simples alteração na redação da lei contribuiu para o aumento no índice de adesão dos indivíduos que ingressavam no serviço público aos planos disponíveis pela FUNPRESP-EXE.

Conforme visto, a principal motivação para a alteração legislativa foi a baixa adesão dos servidores ao plano. Desta forma, através da análise documental realizada, constatou-se que até o ano de 2015, a adesão dos novos servidores aos planos de 
previdência complementar foi inferior a 9\%. Após a mudança na redação da lei no final do ano de 2015, houve aumento vertiginoso nas adesões, chegando ao patamar de $88 \%$ de inscritos, patamar que tem se mantido estável.

Além da implementação das adesões automáticas, foram realizadas campanhas de conscientização dos servidores para aderirem ao programa de previdência por meio de adesões voluntárias: por meio eletrônico ou por meio de preenchimento de formulários. As informações sobre os planos existentes eram disponibilizadas com transparência, fácil acesso e valorizando a autonomia dos servidores (Pena, 2017).

A análise dos dados secundários contidos no sitio da FUNPRESP evidenciou que no ano de 2017, enquanto o total de adesões automáticas correspondeu a $45 \%$ do total de participantes, 55\% correspondeu a adesões voluntárias. Ou seja, o número de pessoas que resolveu se filiar ao plano de previdência espontaneamente foi maior do que o número de pessoas inscritas automaticamente. As iniciativas como a simplificação e clareza das informações contribuem para o sucesso na busca por novas adesões e diminuição do número de desistências.

Até o ano de 2017 foram contabilizadas 16.947 adesões de forma automática e 1.750 desistências, ou seja, apenas $11 \%$ das pessoas inscritas automaticamente se valeram das prerrogativas de desfiliação a qualquer tempo contidas no $\S 3^{\circ}$ do artigo $1^{\circ}$ da lei nº13.183/2015. As desistências após a inscrição automática fazem parte do jogo e que muitas delas são motivadas pelo fato de os participantes estarem contribuindo com um percentual maior do que o desejado (Choi, Laibson, \& Madrian, 2005).

Em um curto período de tempo, de 2016 a 2020, a FUNPRESP aumentou consideravelmente seu número de participantes e patrimônio. Baseada em dados extraídos do portal da instituição, a, Tabela 1 demonstra em números este crescimento:

Tabela 1. Variação anual do número de participantes e patrimônio da FUNPRESP (2016 - 2020), Brasil.

\begin{tabular}{ccccc}
\hline Mês/ano & $\mathbf{N}^{\mathbf{0}}$ part. & Var. part. (\%) & Patrimônio & Var. pat. (\%) \\
\hline FEV/16 & 23.154 & - & 239.000 .000 & \\
\hline FEV/17 & 39.649 & $71 \%$ & 460.000 .000 & $92 \%$ \\
\hline FEV/18 & 57.079 & $44 \%$ & 823.000 .000 & $79 \%$ \\
\hline FEV/19 & 75.741 & $33 \%$ & 1.500 .000 .000 & $82 \%$ \\
\hline FEV/20 & 95.402 & $26 \%$ & 2.580 .000 .000 & $72 \%$ \\
\hline JUN/20 & 97.068 & $2 \%$ & 2.870 .000 .000 & $11 \%$ \\
\hline
\end{tabular}

Fonte: Autores.

Poucos meses depois da publicação da lei alterando o padrão de inscrições aos planos de previdência da FUNPRESP para inscrição automática, o plano de previdência contava com 23.154 participantes. Um ano depois, em 2017, houve crescimento de $71 \%$, aumentando para 39.649. Em 2018 o crescimento de participantes foi de 44\%, no ano de 2019, 33\% e no ano de 2020, $26 \%$. O crescimento acumulado do número de participantes no plano de previdência complementar entre os anos de 2016 a 2020 foi de $312 \%$. O crescimento patrimonial por sua vez manteve sempre patamares superiores a $70 \%$.

Já a Tabela 02 mostra a relação entre a variação do número de participantes da FUNPRESP e o número de servidores ativos entre os anos de 2016 e 2020. 
Tabela 2. Relação entre a variação do número de participantes da FUNPRESP e o número de servidores ativos, (2016 - 2020), Brasil.

\begin{tabular}{ccccc}
\hline Mês/ano & $\mathbf{N}^{\mathbf{0}}$ part. & Var. part. (\%) & $\mathbf{N}^{\mathbf{0}}$ serv. Ativos & Var. serv. (\%) \\
\hline FEV/16 & 23.154 & & 626.465 & \\
\hline FEV/17 & 39.649 & $71 \%$ & 630.893 & $0,71 \%$ \\
\hline FEV/18 & 57.079 & $44 \%$ & 632.973 & $0,33 \%$ \\
\hline FEV/19 & 75.741 & $33 \%$ & 621.421 & $-1,83 \%$ \\
\hline FEV/20 & 95.402 & $26 \%$ & 604.230 & $-2,77 \%$ \\
\hline JUN/20 & 97.068 & $2 \%$ & 599.979 & $-0,70 \%$ \\
\hline
\end{tabular}

Fonte: Autores.

É compreensível o aumento de participantes nos primeiros anos de funcionamento da adesão automática. Isto porque houve aumento também no número de servidores ativos no governo federal. Entretanto, a partir de 2019, com a redução da realização de concursos públicos, o número de novos servidores diminuiu, acompanhado do aumento no número de aposentadorias no período, o que culminou na diminuição no número de servidores ativos.

Com base nos dados extraídos do Painel PEP e Portal da Transparência, verificou-se que entre os anos de 2018 e 2019 houve diminuição de 1,83\% no número de servidores ativos e entre os anos de 2019 e 2020, diminuição de 2,77\%. Mesmo com a diminuição do número de servidores da ativa, dados extraídos do portal da FUNPRESP apontam aumento no número de adesões, ou seja, de adesões voluntárias, o que indica mudança na percepção dos servidores a respeito do plano de previdência privada ofertado.

Tal mudança de comportamento pode ter sido em decorrência das campanhas realizadas pela FUNPRESP a fim de fomentar a transparência em seus procedimentos e o espírito de autonomia nos servidores, e desfazer possíveis incompreensões acerca dos planos por meio do esclarecimento dos pontos mais críticos a respeito do assunto. Um aspecto utilizado pelos dirigentes da fundação na busca por novos participantes que vale ser destacado foi conhecimento a respeitos dos vieses cognitivos que influenciam os indivíduos na tomada de decisão.

A este respeito, a análise documental realizada evidenciou que os dirigentes da FUNPRESP mapearam as principais heurísticas e vieses $(\mathrm{H} \& \mathrm{~V})$ cognitivos que interferiam no comportamento das pessoas frente a decisões relacionadas a investimentos em programas de previdência privada a fim de elaborar as campanhas de captação de novos clientes. De acordo com as informações extraídas dos documentos analisados as H\&V mapeadas foram: aversão a perda, viés do status quo e miopia.

A aversão a perda aumenta a propensão das pessoas a valorizar mais as perdas do que ganhos futuros proporcionais. Com esta informação, os gestores da FUNPRESP compreenderam que a decisão entre investir num plano de previdência cujos benefícios só poderiam ser gozados futuramente contribuía para que as pessoas evitassem se arriscar neste tipo de empreendimento. Além disso, perceberam que através do viés do status quo os servidores em geral permaneciam ligados a seus pontos de referência, ou seja, avessos a terem qualquer tipo de prejuízo ou de realizarem investimentos com resultados a longo prazo. Desta forma, a "falta de visão" de futuro contribui para o fortalecimento do viés da miopia fazendo com que os indivíduos deixassem os investimentos sempre para depois, avaliando de forma imprecisa os resultados presentes em relação aos resultados futuros.

Neste contexto, as campanhas de adesão de novos participantes tiveram papel essencial para mitigar os efeitos das $\mathrm{H} \& \mathrm{~V}$. Combinadas com a adoção da adesão automática, serviram para alterar o ponto de referência dos servidores no processo decisório e contribuíram o alcance do objetivo da política. 
O presente artigo buscou demonstrar a influência da Economia Comportamental no desenho da lei nº 12.618/2012. Por meio do estudo de caso da referida lei buscou-se analisar os dados secundários contidos nos portais da FUNPRESP, Transparência e Painel PEP a fim de compreender os efeitos da intervenção comportamental nos resultados da política.

A intervenção comportamental feita na lei $\mathrm{n}^{\circ} 12.618 / 2012$ possibilitou um aumento significativo no número de participantes da previdência complementar por meio da adoção da adesão automática. Antes da intervenção o número de novos servidores que optaram em aderir ao plano de previdência foi inferior a 9\%. Entretanto com a alteração da lei este percentual passou para $88 \%$, sendo que apenas $11 \%$ dos inscritos automaticamente no plano desistiram de continuar vinculados.

Além da adoção da adesão automática e de fomentar a transparência em seus processos, a astucia dos gestores da FUNPRESP passou pela identificação dos vieses e heurísticas que interferiam na tomada de decisão dos novos servidores e que foram utilizados como informações preciosas para conduzir as campanhas de adesão de novos participantes, a saber: aversão a perda, o viés de status quo e a miopia (ou procrastinação).

No caso estudado, as pessoas demonstraram estar mais preocupadas em se protegerem dos riscos de sofrerem alguma perda do que em buscarem formas de obterem ganhos futuros. O investimento em uma previdência complementar sob o prisma do tempo presente, pode ser visto como um prejuízo e um dispêndio de recursos desnecessários.

Entretanto, o investimento servirá de poupança para a pessoa em momento futuro, proporcional ao montante investido. Mesmo com o apelo de uma aposentadoria mais confortável e despreocupada do ponto de vista financeiro, quando se trata de livre adesão a planos de previdência privada, a alternativa adotada pela maior parte dos indivíduos é a de evitar correr riscos.

Ao ingressarem no serviço público, na vigência do texto original da lei no 12.618/2012, as pessoas tinham como padrão, e, por conseguinte como ponto de partida, a não adesão ao plano de previdência. E de acordo com o viés de status quo, estes servidores tenderiam a se manter no ponto de onde partiram, ou seja, continuariam sem aderir ao plano, fato este que foi observado. Conforme visto, até a publicação da lei no 13.183/2015, menos de $9 \%$ dos novos servidores aderiu à previdência complementar, um percentual considerado baixo para justificar a criação e existência de uma fundação específica para estes fins.

Tanto é que o "fracasso" inicial serviu de motivação para alteração do padrão para adesão automática. No mesmo sentido, como o ponto de referência dos novos servidores passou a ser a adesão automática, a maior parte dos servidores continuaram vinculados ao plano de previdência. Conforme visto, o número de participantes da previdência atingiu o patamar de $88 \%$ de participação dos novos servidores. Desta forma, os dirigentes se utilizaram do mesmo viés cognitivo que estava contribuindo para o fracasso do negócio para alavancar de vez a previdência complementar dos servidores federais.

Ficou evidenciado que a utilização dos conhecimentos da Economia Comportamental na lei $\mathrm{n}^{\mathrm{o}}$ 12.618/2012 potencializou sobremaneira os resultados da política. Entretanto, por se tratar da análise de um caso específico, não se tem indícios suficientes para se generalizar a eficácia das intervenções comportamentais em políticas públicas.

Desta forma, estudos de outras políticas da mesma natureza são necessários e quem sabe até a criação de uma instituição brasileira especializada em propor e criar políticas públicas de cunho comportamental. No mesmo sentido, avaliações mais aprofundadas do processo de tomada de decisões dos indivíduos diante de determinados mecanismos de intervenção comportamental também são uteis, na medida em que ajudam a prevenir situações em que as decisões são tomadas influenciadas pelo viés da inércia ou acomodação.

\section{Referências}

Bhargava, S., \& Loewenstein, G. (2015). Behavioral economics and public policy 102: Beyond nudging. American Economic Review, 105(5), 396-401. https://www.aeaweb.org/articles?id=10.1257/aer.p20151049.

Brasil. (2012). Decreto no 7.808, de 20 de setembro de 2012. Dispõe sobre a criação da Funpresp-Exe. 
Research, Society and Development, v. 10, n. 1, e0610110979, 2021 (CC BY 4.0) | ISSN 2525-3409 | DOI: http://dx.doi.org/10.33448/rsd-v10i1.10979

Camerer, C. F. (2014). Behavioral economics. Current Biology, 24(18), R867-R871. https://www.scienced irect.com/science/article/pii/S0960982214009038.

Campos Filho, A. C., \& Paiva, L. H. D. S. D. (2018). Economia Comportamental Aplicada às Políticas Públicas. https://repositorio.enap.gov.br/handle/1/3127.

Choi, J. J., Laibson, D. I., \& Madrian, B. C. (2005). Are empowerment and education enough? Underdiversification in 401 (k) plans. Brookings papers on economic activity, 2005(2), 151-213. https://www.brookings.edu/wp-content/uploads/2005/06/2005b_bpea_choi.pdf.

Contel, F. B. (2011). Território e finanças: técnicas, normas e topologias bancárias no Brasil (Doctoral dissertation, Universidade de São Paulo). https://www.teses.usp.br/teses/disponiveis/8/8136/tde-01062007-135730/publico/TESE_FABIO_BETIOLI_CONTEL.pdf.

Creswell, J. W. (2010). Mapping the developing landscape of mixed methods research. SAGE handbook of mixed methods in social \& behavioral research, 2 , 45-68. https://methods.sagepub.com/book/sage-handbook-of-mixed-methods-social-behavioral-research-2e/n2.xml.

Federal, Governo. Controladoria-Geral da União(CGU): Portal da Transparência. 2020. https://www.gov.br/cgu/pt-br/assuntos/transparencia-publica/portal-datransparencia.

Federal, Governo. Ministério da Economia. Painel Estatístico de Pessoal. https://www.gov.br/economia/pt-br/assuntos/planejamento/servidores/painelestatistico-de-pessoal.

Godoy, A. S. (1995). Introdução à pesquisa qualitativa e suas possibilidades. RAE-revista de administração de empresas, 35(2), 57-63. https://rae.fgv.br/rae/vol35-num2-1995/introducao-pesquisa-qualitativa-suas-possibilidades.

Investidor Institucional. Revista do investidor institucional. https://www.investidorinstitucional. com.br/component/flippingbook/book/161-investidorinstitucional-321-dez2019-jan2020/1-revistainvestidorinsti tucional.html?Itemid=1504.

Low, D. (2012). Introduction: Cognition, Choice and Policy Design. In Behavioural Economics And Policy Design: Examples from Singapore (pp. 1-13).

Lüdke, M., \& André, M. E. D. A. (1986). Abordagens qualitativas de pesquisa: a pesquisa etnográfica e o estudo de caso. São Paulo: EPU, 11-24.

Samson, A. (2014). The behavioral economics guide 2014 (with a foreword by George Loewenstein and Rory Sutherland). http://eprints.lse.ac.uk/58027/.

Simon, H. A. (1955). A behavioral model of rational choice. The quarterly journal of economics, 69(1), 99-118. https://academic.oup.com/qje/articleabstract/69/1/99/1919737.

Simon, H. A. (1978). Rationality as process and as product of thought. The American economic review, 68(2), 1-16. https://www.jstor.org/stable/1816653?seq=1.

Soman, D. (2015). The last mile: Creating social and economic value from behavioral insights. University of Toronto Press. https://utorontopress.com/us/thelast-mile-4.

Sousa Lourenco, J., Ciriolo, E., Rafael Almeida, S., \& Dessart, F. (2016). Behavioural Insights Applied to Policy-Country Overviews 2016 (No. JRC100547). Joint Research Centre (Seville site). https://ec.europa.eu/jrc/en/publication/thematic-reports/behavioural-insights-applied-policy-country-overviews-2016.

Starmer, C. (2015). Entendendo preferências: o que podemos aprender com a economia comportamental. Ávila, Flávia; Bianchi, Ana Maria. Guia de Economia Comportamental e Experimental. São Paulo: Economiacomportamental. org, 60-75. http://www.economiacomportamental.org/guia-economiacomportamental.pdf.

Tabak, B. M., \& Amaral, P. H. R. (2018). Vieses cognitivos e desenho de políticas públicas. Revista Brasileira de Políticas Públicas, 8(2), 472-491.

Team, B. I. (2014). EAST: Four simple ways to apply behavioural insights. Behavioural Insight Team, London.

Thaler, R. H., \& Sunstein, C. R. (2009). Nudge improving decisions about health, wealth, and happiness. Penguin. 
Research, Society and Development, v. 10, n. 1, e0610110979, 2021

(CC BY 4.0) | ISSN 2525-3409 | DOI: http://dx.doi.org/10.33448/rsd-v10i1.10979

Vidal, L. F. M. (2018). Economia comportamental e alfabetização financeira no Brasil: impactos na previdência privada. https://tede2.espm.br/handle/tede/327.

World bank (2019). “World Development Report: Mind, Society and Behavior”. World Bank Group. https://www.worldbank.org/en/programs/embed. 